\title{
Identificación de elementos del paisaje urbano que fomentan la caminata en Santiago
}

\section{Identification of elements of the urban landscape which encourage walking in Santiago}

\author{
Marie Geraldine Herrmann-Lunecke \\ ORCID: https://orcid.org/0000-0003-0186-441X \\ Departamento de Urbanismo, Universidad de Chile, Santiago, Chile. Correo electrónico: mherrmann@uchile.cl
}

\author{
Rodrigo Mora \\ ORCID: https://orcid.org/0000-0003-2162-0076 \\ Departamento de Urbanismo, Universidad de Chile, Santiago, Chile.
}

\author{
Paloma Véjares \\ ORCID: https://orcid.org/0000-0002-8207-9028 \\ Universidad Diego Portales, Santiago, Chile.
}

Esta investigación fue financiada por CONICYT Proyecto Fondecyt Regular №1170292.

Se agradece a CEDEUS (Centro de Desarrollo Urbano Sustentable) y a las asistentes de investigación Soledad Monsalve y Carla Morales.

\section{Resumen}

Caminar es un modo de transporte sustentable y saludable, que debería ser promovido mediante la planificación y el diseño urbano. En este contexto, la presente investigación tiene como objetivo identificar los elementos del paisaje urbano que, desde la percepción del caminante, facilitan la caminata y, en contraste, los elementos que la inhiben, dentro de seis barrios pericentrales del Gran Santiago. Con este fin, se realizaron 120 walking interviews (entrevistas caminando in situ) con residentes durante septiembre, octubre y noviembre de 2018, permitiendo un detallado registro de la percepción auto-declarada de los peatones sobre sus entornos de movilidad peatonal. Los resultados muestran que elementos que promueven la caminata son la presencia de veredas anchas, árboles y uso de suelo mixto. En contraste, elementos que inhiben la caminata son veredas angostas y en mal estado, los cruces y, en especial, el tráfico motorizado y el ruido vehicular. Finalmente, en base a los resultados, se proponen recomendaciones para una planificación y un diseño de calles que promuevan la caminata.

Palabras clave

Caminabilidad, diseño urbano, movilidad peatonal, percepción, veredas

\begin{abstract}
Walking is a sustainable and healthy transport mode, which should be promoted through urban planning and design. In this context, the objective of this research is to identify and characterise the elements of the urban landscape which promote walking and, contrarily, the elements which inhibit walking in six peri-central neighbourhoods in Santiago, based on the perception of walkers. With this aim, 120 walking interviews were realised during September, October and November 2018 with residents, allowing for a detailed record of the self-declared perception of pedestrians about their urban mobility environments. Results show that elements which promote walking are the presence of wide sidewalks, trees and mixed use. In contrast, factors that inhibit walking are narrow sidewalks, intersections, and especially motorized traffic and vehicular noise. Finally, based on the results, recommendations are proposed for the planning and design of streets that promote walking.
\end{abstract}

\section{Keywords}

Pedestrian mobility, perception, sidewalks, urban design, walkability 


\section{Introducción}

En Chile la reciente Política Nacional de Desarrollo Urbano (Ministerio de Vivienda y Urbanismo, 2014) define como objetivo promover la caminata en las ciudades, reconociendo la importancia de la caminata como modo de transporte saludable y sustentable. No obstante, los espacios públicos peatonales en Chile carecen de un apropiado diseño y presentan una serie de problemas en su entorno físico-espacial que inhiben la caminata (Herrmann-Lunecke, 2006, 2016). En general, las calzadas de las calles suelen estar sobredimensionadas (7 m), mientras que las veredas están subdimensionadas, teniendo estas últimas en muchos casos un ancho de no más de 1,2 m. En otras calles -en especial en barrios de menores ingresos- las veredas ni siquiera existen o no están pavimentadas, no cuentan con accesibilidad universal o tienen una arborización escasa o inexistente. Estos problemas de diseño son acentuados por conductas como el uso de las veredas para estacionamiento de automóviles y/o ciclos, o la obstrucción de aceras mediante postes de luz, señales de tránsito y publicidad.

Investigaciones internacionales muestran que uno de los aspectos claves para el fomento de la caminata es el entorno construido. En efecto, varios estudios han buscado identificar las variables urbanas que se relacionan con un aumento en la caminata o con una mayor predisposición de la gente para caminar (Adkins, Makarewicz, Scanze, Ingram, \& Luhr, 2017; Ewing \& Cervero, 2001; Ewing \& Cervero, 2010; Handy, Boarnet, Ewing \& Killingsworth, 2002; Heath et al., 2006; Sealens \& Handy, 2008; ValenzuelaMontes \& Talavera-García, 2015). Cabe señalar, que en Chile son escasas las investigaciones que analizan cuales son los factores físicos del entorno construido que promueven la caminata en nuestro entorno local (Figueroa, Hodgson, Mullen \& Timms, 2019). Estudios que revelen cuales son los elementos del paisaje urbano que fomentan la caminata en un determinado contexto local, pueden ser de gran relevancia para informar a las políticas de movilidad y el diseño urbano.

En este contexto, la presente investigación tiene como objetivo identificar y caracterizar los elementos del paisaje urbano que facilitan la caminata y, en contraste, identificar y caracterizar los elementos del paisaje urbano que inhiben la caminata, desde la percepción del caminante. Los casos de estudio son seis barrios pericentrales del Gran Santiago, con distintas características socioeconómicas y localizados en torno a estaciones de Metro (Ecuador, San Alberto Hurtado, Cumming, Santa Ana, Francisco Bilbao y Cristóbal Colón). Se realizaron 120 walking interviews (entrevistas caminando) con residentes de estos barrios en primavera durante septiembre, octubre y noviembre de 2018, permitiendo así un detallado registro in situ de la percepción auto-declarada de los peatones sobre sus entornos de movilidad peatonal. A continuación, los datos obtenidos mediante los 120 walking interviews fueron codificados y procesados con el software Atlas. ti, mostrándose con claridad aquellos elementos -y las características de estos- que promueven la caminata y, en contraste, aquellos elementos que inhiben la caminata en barrios pericentrales de Santiago.

Este artículo se divide en cuatro partes. La primera parte introduce el marco teórico conceptual respecto al entorno construido y su impacto en la caminata. A continuación se explica el enfoque metodológico (walking interview) y el análisis de datos (software Atlas.ti). Posteriormente, se muestran y discuten los resultados obtenidos en esta investigación respecto a elementos que facilitan y dificultan la caminata en barrios pericentrales del Gran Santiago. Finalmente, en base a los resultados, se entregan conclusiones que reflexionan entorno a una planificación y un diseño de calles que promuevan la caminata en las ciudades.

\section{Caminar y paisaje urbano}

Caminar en la ciudad provee de muchos beneficios a los habitantes urbanos. Caminar no contamina, es una práctica cotidiana urbana (Jirón e Imilán Ojeda, 2018), y contribuye a mejorar la salud física y mental de las personas (Bopp, Kaczynski \& Campbel, 2013; Hill, Wyatt, Reed \& Peters, 2003; Morgan, Tobar \& Snyder, 2010; Williams \& Thompson, 2013). De hecho, se ha demostrado que la caminata puede contribuir a reducir significativamente el exceso de grasa corporal e influir 
positivamente sobre los factores asociados a salud cardiovascular (Williams \& Thompson, 2013; Morgan, Tobar \& Snyder, 2010). Otros estudios muestran que las personas que caminan o van en bicicleta al trabajo se sienten más saludables que quienes utilizan transporte público o su propio automóvil (Bopp, Kaczynski \& Campbel, 2013) y que caminar permite liberar tensión y reducir el estrés, incluso pudiendo ayudar a dormir mejor (Center for Disease Control and Prevention, 2012). Asimismo, el peatón aporta significativamente a la vitalidad (Gehl \& Gemzo, 1996; Jacobs, 1961; Loukaitou Sideris \& Ehrenfurcht, 2009; Whyte, 1980) y a la seguridad en el espacio público urbano (Hillier, 1996).

En este contexto, han surgido a partir de los años noventa los conceptos de "caminabilidad" (walkability) y de "entornos caminables" (walkable environments). Estos conceptos subrayan la importancia que la infraestructura física y los entornos socio-espaciales puede tener sobre la caminata y la predisposición de las personas para caminar (Dovey \& Pafka, 2020), planteando que una mayor "caminabilidad" de barrios o ciudades debería conllevar a un aumento en la caminata de las personas (Forsyth, 2015; Loukaitou-Sideris \& Ehrenfurcht, 2009; Speck, 2012).

La literatura internacional muestra que el entorno físicoespacial puede tener un rol fundamental en promover o inhibir la caminata en cuanto a modo de "vida activa" (Brown, Werner, Amburgey \& Szalay, 2007; Cervero \& Kockelman, 1997; Krizek, Handy \& Forsyth, 2009; Saelens \& Handy, 2008; Sallis et al, 2016; Sallis, Floyd, Rodríguez, \& Saelens, 2012). Por este motivo, estudios internacionales han analizado las variables físicoespaciales que facilitan o inhiben la caminata (Ewing \& Cervero, 2001; Rodríguez \& Joo, 2004; Stronegger, Titze \& Oja, 2010; Valenzuela-Montes y Talavera-García, 2015; Zacharias, 2001). La mayoría de las investigaciones sobre caminata se han centrado en aspectos macro escalares (Arellana, Saltarín, Larrañaga, Alvarez \& Henao, 2019, Steinmetz-Wood, Velauthapillai, O’Brien, \& Ross, 2019), y han mostrado, por ejemplo, que variables como la densidad poblacional, la conectividad y la mixtura de usos influencian positivamente la disposición de la gente a caminar (Cervero \& Kockelman, 1997; Dovey \& Pafka, 2020; Ewing \& Cervero, 2010; Leslie et al., 2005; Van Dyck et al., 2012). Asimismo, Rodríguez y Joo (2004) encontraron que la presencia de veredas y una topografía plana está fuertemente asociada a la elección de modos de desplazamiento no motorizados, especialmente la caminata. En la misma línea, se ha mostrado que la densidad residencial está positivamente asociada a la adopción de modos de transporte no motorizados, como caminata y bicicleta (Ewing \& Cervero, 2010). También, Stronegger, Titze y Oja (2010) encontraron una correlación importante entre la realización de actividad física regular, y las características del barrio, específicamente la presencia de servicios y transporte público.

Por otro lado, diversos estudios han analizado el rol de variables "micro" del entorno construido, como el ancho de las veredas, presencia de árboles o existencia de bancas, como elementos que fomentan la caminata, a través de lo que se conoce como "auditorías de caminata" (walking audits) o "entrevistas caminando" (walking interviews) (Sallis et al., 2015; Cain et al., 2018). La mayoría de estas técnicas buscan registrar la percepción de las personas sobre el entorno construido a partir de auto-relatos de caminantes que recorren las calles. Otras técnicas para el análisis de variables micro del medio construido se han realizado mostrando a las personas imágenes puntuales de calles, provenientes de plataformas como Google Earth (Hanibuchi, Nakaya e Inoue, 2019; Rossetti et al., 2019). Cabe destacar, que las "entrevistas caminando" tienen la ventaja de ser realizadas en situ, recorriendo la calles y estando en movimiento, lo que les otorga mayor validez ecológica, dado que variables ambientales (temperatura, ruido, olores, etc.) y sociales (presencia de personas, etc.) en las calles inciden en la experiencia de la caminata. Es importante destacar, que los estudios sobre percepción de entornos físicos de movilidad peatonal son de gran interés para la arquitectura y el diseño de calles -que hoy obedece a parámetros de diseño predominantemente ingenieriles y orientados al automóvil-al arrojar resultados acerca de las preferencias de los peatones en relación a su entorno físico urbano (Clifton, Livi \& Rodríguez, 2007), que pueden informar al diseño arquitectónico de nuestras calles y espacios públicos. 
A nivel nacional en Chile, son varios los estudios que han abordado temas relacionados con la caminabilidad. Por ejemplo, Pavez Reyes (2013) sostiene la necesidad de incrementar la "peaseabilidad" de la ciudad, mientras que Mora y Zapata (2004) analizan cómo la planificación urbana local puede crear las condiciones morfológicas para aumentar la caminabilidad y vitalidad urbana. Otros estudios han analizado el impacto del entorno construido sobre la percepción de inseguridad al caminar (Sillano, Greene \& Ortúzar, 2006). Por su parte, Figueroa et al. (2019), Figueroa y Forray (2015), Sagaris \& TizandoAitken (2020) y Jirón \& Gómez (2018) han mostrado que la percepción de la caminabilidad de las calles tiene fuertes diferencias de género, afectando especialmente a las mujeres en barrios de menores ingresos, quienes se sienten más inseguras al caminar. Sin embargo, faltan en Chile estudios que analicen en forma más exhaustiva cuáles son los factores físico-espaciales del paisaje urbano que promueven y/o inhiben la caminata en nuestro contexto local.

Entender la idea de paisaje urbano requiere primeramente conocer qué se entiende por paisaje. Maderuelo señala que el paisaje es una producción intelectual, es "«lo que se ve», no «lo que existe»" (Maderuelo, 2010, 575), por lo que es, en gran medida, subjetivo. Eso no significa que el paisaje sea enteramente subjetivo, por cuanto la percepción se hace sobre elementos reales, existentes, que son interpretados por las personas. Al respecto, Lynch (1960) señala que el paisaje urbano se consolida a modo de imagen urbana que, aunque personal y subjetiva debido a su origen en el aparato perceptual de las personas, tiene componentes comunes entre todos quienes habitan la ciudad. Las ciudades, según Lynch, tendrían imágenes bien definidas o débiles, lo que incidiría en la capacidad de éstas de ser recordadas, exploradas y en la capacidad de las personas de tener un vínculo emocional con ellas. Esta condición, entre lo subjetivo y lo objetivo, hace que las definiciones del paisaje urbano sean a menudo contradictorias (Keshtkaran, 2019).

Aproximaciones más recientes al término han buscado, más que definir el término paisaje urbano como tal, definir las dimensiones que éste contempla. Así, Golkar (2008) señala que el concepto paisaje urbano puede ser abordado desde sus dimensiones artísticas, funcionales, perceptuales o ecológicas (Golkar, 2008). Más aún, de acuerdo a Keshtkaran (2019), más que una definición estática y cerrada, el paisaje urbano es una construcción teórica dinámica, sujeta a un intenso debate multidisciplinar en permanente evolución.

La presente investigación releva la importancia de entender el espacio público y entorno construido desde la mirada del caminante, uno de los usuarios más desaventajados en la calle, tanto en términos de seguridad como en asignación de espacio, recursos y calidad de diseño (Berding, Kulinski \& Selle, 2003; HerrmannLunecke, 2006, 2016). Más aún, dentro de los peatones, los usuarios más vulnerabilizados son las mujeres, los niños, las personas en situación de discapacidad y los adultos mayores. Así, la calle constituye un espacio que reproduce e incrementa inequidades (Figueroa et al., 2019; Figueroa et al., 2018) para mujeres (Allen, Cárdenas, Pereyra, \& Sagaris, L, 2019; Figueroa \& Forray; 2015; Jirón, 2013; Jirón \& Gómez, 2018; Mora, Greene y Reyes, 2018; Paydar, Kamani-Fard \& Etminami-Ghasrodashti, 2017), niños (Tonucci, 2004), personas en situación de discapacidad (Gaete-Reyes, 2017) y adultos mayores (Kenyon, Lyons \& Rafferty, 2002; Yuen, 2019).

\section{Metodología}

Esta investigación busca identificar aquellos elementos del paisaje urbano que, desde la percepción del caminante, facilitan la caminata $\mathrm{y}$, en contraste, aquellos elementos que inhiben la caminata en barrios pericentrales del Gran Santiago. Con este fin se seleccionaron seis barrios representativos del pericentro del Gran Santiago, con distintas características socioeconómicas (GSE). Para seleccionar los barrios se analizaron los barrios pericentrales del Gran Santiago localizados en torno a estaciones de Metro en base a visitas a terreno y revisión cartográfica (INE, 2002; IDE, 2017) (Herrmann-Lunecke, Mora \& Monsalve, 2020). Posteriormente, los barrios se examinaron en cuanto a su cercanía al Metro, uso de suelo, tipologías edificatorias, altura de edificación, 
densidad, trama urbana, listado de juntas de vecinos activas, y, nivel socioeconómico promedio por manzana. En base a este análisis, se seleccionaron seis barrios representativos con juntas de vecinos activas (Figura 1): dos barrios de GSE bajo/medio-bajo=Barrio San Alberto Hurtado Norte (Metro San Alberto Hurtado) y Barrio Ecuador Norte (Metro Ecuador) (Comuna de Estación Central); dos barrios de GSE medio=Barrio Santa Ana (Metro Santa Ana) y Barrio Cumming (Metro Cumming) (Comuna de Santiago); y, dos barrios de GSE medio-alto/alto=Barrio Pocuro Norte (Metro Cristóbal Colón) y Barrio Las Flores (Metro Francisco Bilbao) (Comuna de Providencia) (Herrmann-Lunecke, Mora \& Monsalve, 2020). Cabe destacar, que se analizaron barrios pericentrales, ya que éstos debido a su buena conectividad con el transporte público (Metro, etc.) y, desde el punto de vista de la planificación urbana, presentan un área de oportunidad para promover y aumentar la caminata diaria hacia el transporte público como modo de transporte sustentable.

Los participantes para las walking interview (entrevista caminando) fueron reclutados con la ayuda de las juntas de vecinos y a partir de letreros colocados en el comercio local. Todos los participantes debían ser residentes del barrio hace al menos dos años, mayores de edad y hablar español. El estudio contó con la participación de 120 personas (20 por cada barrio), de las cuales 60 personas eran mujeres. Se incluyeron como participantes a adultos jóvenes (18-29 años), adultos (30-59 años) y adultos mayores (sobre 60 años), siendo el rango de edad entre 18 y 80 años. Esto permitió analizar diferencias de percepción según edad, género y contexto socioeconómico.
Se realizó una walking interview con cada participante, con el fin de registrar la percepción auto-declarada de los residentes sobre su entorno urbano mientras caminaban. A cada participante se le pidió que realice un recorrido predeterminado de $600 \mathrm{~m}$ en su vecindario ${ }^{1}$, recorrido que iba desde el interior del barrio en un entorno residencial hacia el Metro, localizado en una calle principal de alto tránsito. Acompañado por una/un guía (walking guide), se le pidió a cada participante que narre de forma libre su experiencia de caminata y que señale qué elementos facilitaban su caminata y qué elementos inhibían su caminata, expresando sus emociones al caminar (por ejemplo, "esta vereda es muy angosta, y me hace sentir inseguro”). La conversación fue grabada con una cámara georeferenciada, para poder verificar la localización de cada registro. Cabe señalar que la conversación no era estructurada y que la/el guía no intervenía, excepto cuando se producían situaciones de extenso silencio para motivar al caminante a continuar con su relato auto-declarado. Las walking interviews se realizaron en días de semana, en las mañanas en primavera, durante los meses de septiembre, octubre y noviembre de 2018. Las entrevistas fueron transcritas y procesadas en el software de análisis cualitativo Atlas.ti. Basándose en el procedimiento de codificación abierta descrito en el método de la Teoría Fundada (Charmaz, 2006; Strauss \& Corbin, 1990), se codificaron en las entrevistas: i) los elementos del entorno construido (por ejemplo, árbol, cruce, vereda, etc.), ii) las características de los elementos (por ejemplo, angosto, deteriorado, con hoyos, etc.), y iii) las emociones auto-declaradas que generaban los elementos del paisaje urbano en los caminantes. Las emociones fueron codificadas de acuerdo con la clasificación de Damasio (1994) en emociones de fondo (bienestar, malestar/estrés; seguridad, inseguridad)

1 Para cada uno de los seis barrios pericentrales seleccionados, se identificó un recorrido "tipo", es decir un recorrido que gran parte de los habitantes del barrio utilice diariamente para ir al Metro. Esto con el fin de estudiar recorridos de la misma índole y aquellos que las personas realizan en la vida cotidiana, habitualmente. Los recorridos tuvieron una extensión de $600 \mathrm{~m}$, medida internacionalmente asociada al umbral de caminata peatonal, y que ha sido validada en estudios de la red de Metro a nivel nacional (Cámara Chilena de la Construcción, 2013). Cabe señalar que los recorridos predeterminados "tipo" fueron definidos a partir de la realización de mapeos proyectivos con las respectivas juntas de vecinos, donde los mismos residentes identificaban los recorridos que realizan habitualmente para caminar al Metro. A continuación, se aunaron todas las posibles rutas en un plano final y se seleccionó como recorrido "tipo" la más habitual en base a frecuencia de mención. En el marco de esta investigación se realizaron 10 eventos participativos con las juntas de vecinos y se aplicaron 154 técnicas de mapeo proyectivo entre noviembre 2017 y junio de 2018 (Herrmann-Lunecke, Mora \& Monsalve, 2020). 


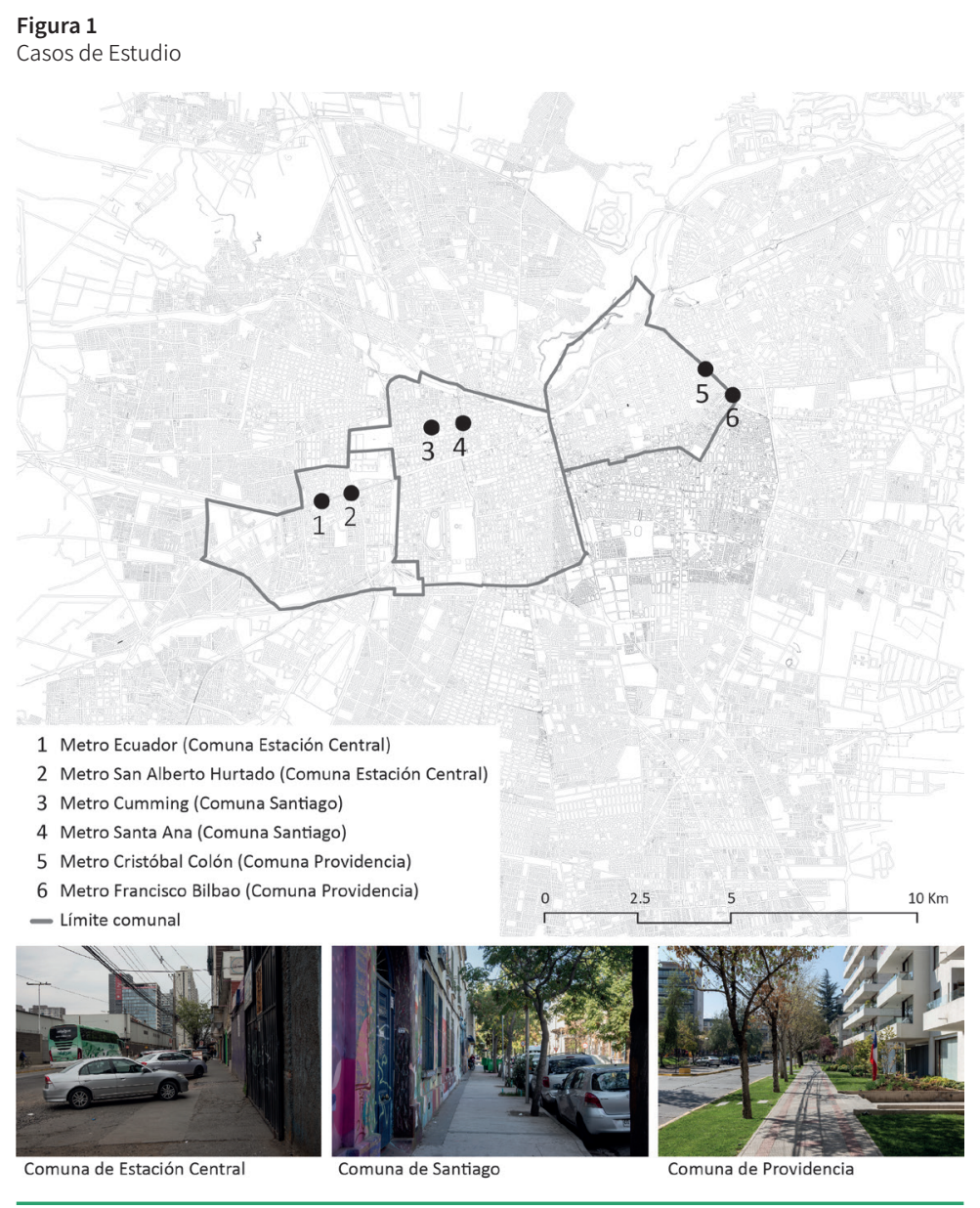

Fuente: Elaboración propia.

y emociones primarias (alegría, tristeza, miedo, ira, repugnancia) ${ }^{2}$. Esto permitió mostrar que elementos $-\mathrm{y}$ con que características- generaban bienestar, seguridad y felicidad, facilitando la caminata, y, en contraste, qué elementos -y con qué características- causaban estrés, inseguridad, e incluso miedo, tristeza, ira y repugnancia, inhibiendo el caminar de los residentes.

\section{Resultados y Discusión}

Los resultados se estructuraron en torno a los elementos del paisaje urbano que fueron más frecuentemente mencionados por los residentes y, que según los propios caminantes, más impactaban en su caminar. Así, los elementos más "relevantes" para la caminata -tanto positivos como negativos- emergieron desde el auto- relato de los mismos residentes. Estos fueron la vereda, la edificación, los usos de suelo, el árbol, las áreas verdes, los cruces, el tráfico vehicular y el ruido. Interesantemente el impacto que generaba el paisaje urbano en la caminata no dependía solamente del elemento, sino también de la característica de este elemento, como muestra el análisis de los resultados a continuación.

\section{La vereda}

De acuerdo a los residentes, las veredas eran claves para la experiencia del caminar. De hecho, la vereda fue el elemento más mencionado durante las entrevistas ( $\mathrm{N}=328)$. Evidentemente, la vereda es un elemento fundamental de la infraestructura física para la caminata urbana. La vereda es un espacio lineal de ancho variable, localizado entre el

2 Cabe señalar que una determinada relación, por ejemplo, "esta vereda es muy angosto y me da inseguridad", fue codificada una sola vez por persona, independiente de que la persona repitiera esta relación varias veces durante la caminata. Esto permite comparar la frecuencia con la cual una determinada relación es mencionada en un grupo de personas. 


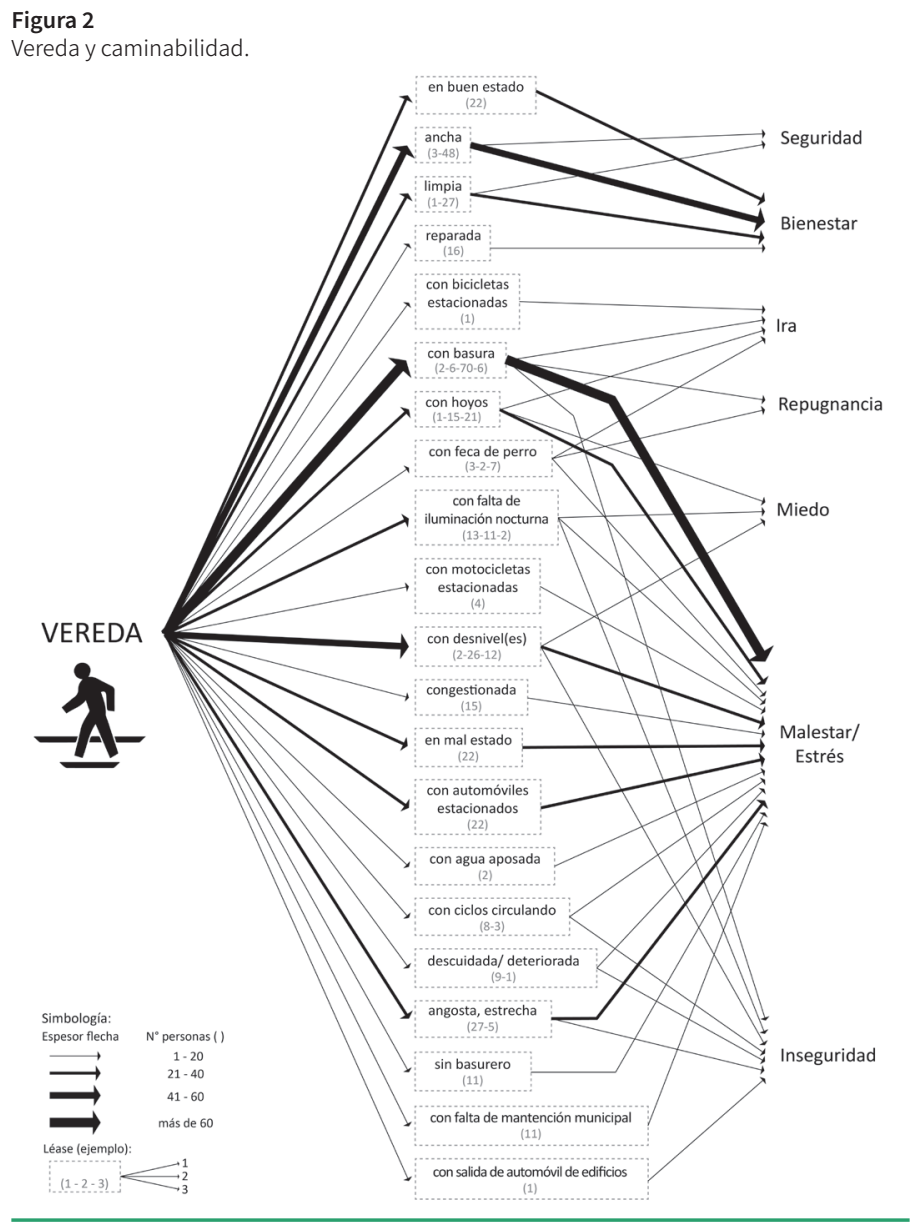

Fuente: Elaboración propia.

espacio privado y la calzada, destinado principalmente al tránsito y al estar de los peatones (aunque con una creciente y disputada ocupación por ciclos). Cabe señalar, que la división de calles en veredas y calzadas es relativamente reciente, pues hasta el siglo XIX la calle era un espacio continuo que albergaba todos los modos de transporte, así como otras actividades públicas (Herrmann-Lunecke, 2016). Recién a inicios del siglo XX emerge la vereda como elemento habitual del diseño urbano -separada de la calzada mediante un desnivel y con distinta materialidad- con el objetivo de incrementar la seguridad vial y facilitar la fluidez del transporte motorizado, en el marco de una planificación orientada fuertemente al automóvil. En este contexto, hoy la red de veredas es el principal espacio peatonal de nuestras ciudades.
Según los residentes, la experiencia del caminar estaba fuertemente determinada no solamente por la presencia de veredas, sino también por las características de éstas (Figura 2) ${ }^{3}$. Así, la vereda ancha fue mencionada por casi la mitad de los caminantes como elemento que facilitaba la caminata, generando bienestar y seguridad al caminar. Interesantemente, la vereda ancha fue mencionada más por mujeres que hombres. Esto podría relacionarse con que muchas mujeres al caminar realizan tareas del cuidado, como son atender niños, ir de compras, etc. (Herrmann-Lunecke, Mora \& Sagaris, 2020), y donde las veredas anchas posibilitan mayor seguridad y confort. Otras características que fueron evaluadas como positivas son las veredas limpias, en buen estado y/o reparadas. En las palabras de una mujer de 39 años (barrio Metro Cumming):

3 Los números entre paréntesis en las figuras (Figura 2 - Figura 8) indican la cantidad de personas que mencionaron una determinada relación. Por ejemplo: "Vereda $\rightarrow$ en buen estado $\rightarrow$ Bienestar" se lee como "Vereda (elemento) en buen estado (característica) genera Bienestar (emoción). El número entre paréntesis indica cuantas personas indicaron esta relación. Cuando hay más de un número, estos se deben leer de izquierda a derecha, y las flechas de arriba hacia abajo. 
Aquí las veredas están bien cuidadas [...]. esta vereda es relativamente ancha, bueno, yo tengo tres hijos. Entonces siempre tengo que ir con ellos de la mano [...] cuando son muy angostas las veredas y cuando pasa eso es complicado, porque voy con el coche con el otro niño y cuesta, entonces tienen que ser veredas anchas. Finalmente, como que en Santiago está pensada la vereda para uso personal, o sea de a uno o dos personas, pero no con niños, coches, mochilas, etc.

Contrariamente, las veredas angostas generaban estrés e inseguridad, acentuando los conflictos entre los distintos usuarios (peatones-ciclos, etc.). Otras características que dificultaban la caminata según los residentes eran las veredas con desniveles, con hoyos, en mal estado y/o con basura, causando malestar e inseguridad, e incluso en algunos caminantes miedo e ira. Cabe destacar, que particularmente los caminantes de la tercera edad declaraban que su caminata se veía severamente impedida por veredas con hoyos y desniveles. Muchos ancianos -en especial de avanzada edad-padecen de alguna limitación de movilidad, fragilidad u otros problemas físicos o mentales (Organización Mundial de la Salud, 2019). Los mayores de 65 años, por ejemplo, son quienes sufren más caídas mortales, y son muy sensibles a cambios de nivel en el pavimento como resaltes y veredas en mal estado. Como expresaba un hombre de 70 años (barrio Metro Colón):

Se le agrega a eso de que las veredas no son muy amigables con las personas que caminan y que son mayores [...]. Yo soy operado, salí a caminar y tengo que hacer verdaderos malabares para no caerme, porque con los bastones las veredas tienen altibajos, le faltan, ¿cómo se llama? Palmetas; las raíces de los árboles a veces las levantan, y a eso se le agrega, además, que con los trabajos que hacen con los edificios, uno tiene que estar yendo de un lado para otro, o rompen los camiones el tema de las veredas, lo que se transforma en un peligro.

Otro aspecto que fue destacado como negativo por los caminantes fueron los automóviles estacionados en la vereda, los cuales obstruían el libre paso peatonal. Asimismo, la falta de iluminación nocturna (aspecto que incidía muy fuerte en la percepción de seguridad), la falta de mantención municipal y los ciclos circulando en las veredas dificultaban considerablemente la caminata.

\section{La edificación}

Otro elemento crucial en la percepción del entorno al caminar fueron las edificaciones. Estas se ubican en los bordes de las veredas y son en su mayoría de carácter privado o semipúblico. De diversas tipologías y alturas, las edificaciones enmarcan el espacio público de la calle, teniendo un fuerte impacto en la experiencia de la caminata. Así, las edificaciones fueron nombradas en total 240 veces por los residentes, siendo el segundo elemento más mencionado después de la vereda. Al igual que en el caso de las veredas, las características de las edificaciones eran determinantes en la experiencia del caminar.

En este sentido, muchos residentes señalaron que la edificación de baja altura (1-2 pisos) y de mediana altura (3-6 pisos) les parecía agradables al caminar (Figura 3). Contrariamente, casi la mitad de las personas indicó que la edificación en altura (más de 8 pisos) era un elemento negativo al caminar. Esto fue particularmente mencionado en los barrios de menores ingresos (Ecuador y San Alberto Hurtado), donde el 90\% de los residentes expresó que la edificación en altura les producía estrés. Cabe señalar, que ambos barrios sufrieron una acelerada densificación y verticalización durante los últimos años, generando las torres fuertes externalidades negativas sobre las viviendas de menor altura y espacios públicos aledaños, al arrojar sombras y restar privacidad (Inzulza-Contardo, 2016; HerrmannLunecke y van Klaveren, 2013). Como señalaba una mujer de 52 años (barrio Metro San Alberto Hurtado):

Es impresionante la cantidad de edificios que hay, que de verdad, visualmente, me molesta mucho. Este era un barrio que eran construcciones bajas de casas, mucha casa, mucho patio, y en cinco años más o menos yo recuerdo, comienza a aparecer 
Figura 3.

Edificación y caminabilidad.

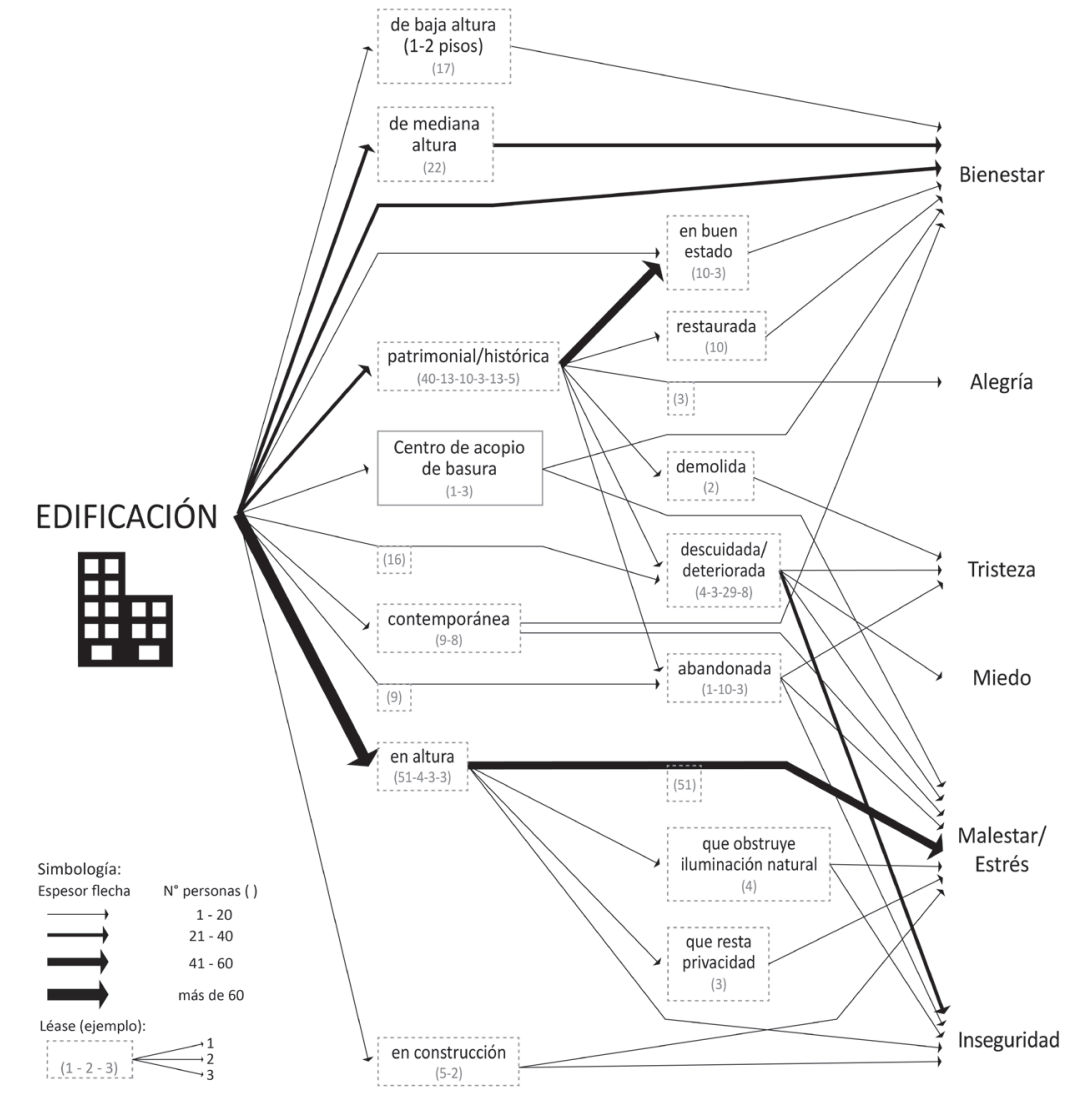

Fuente: Elaboración propia.

muchísimo, muy repentinamente mucho edificio que no me gusta verlo. No son tanto los espacios que están quedando, espacios de áreas verde, espacios de comunidad, negocios de barrio que han sido definitivamente eliminados, o están muy amenazados.

En esta misma línea, otro residente de 55 años (barrio Metro Ecuador) indica:

Donde aquí todo el día es todo el día hay sombra poh, es oscuro. Eso eso no me agrada al caminar, soy de espacio; uno nació en espacios libre, miraba hacia la cordillera y la veía, ahora lamentablemente no ocurre, y eso desde el punto de vista psicológico, me imagino que empieza a mermar la forma de actuar de cada uno poh, se pone más triste, me imagino.

Notablemente, un tercio de los caminantes señaló que la edificación patrimonial les causaba bienestar, y en algunos casos, incluso alegría. Esto revela la valorización que los caminantes de estas comunas pericentrales tienen respecto al patrimonio edificatorio. Sin embargo, la edificación patrimonial demolida, descuidada, deteriorada y/o abandonada generaba malestar e inseguridad, e incluso tristeza, en muchos caminantes.

\section{Los usos de suelo}

También los usos de suelo fueron claves en la percepción de la caminata, y mencionados en total 248 veces. La importancia del uso de suelo sobre la caminata ya ha sido analizada en varios estudios internacionales, mostrando que el uso mixto y la diversidad de usos impacta positivamente la caminata, al proveer una mayor variedad de destinos caminables (Cervero \& Kockelman, 1997; Dovey \& Pafka, 2020). Lo anterior se condice con los resultados de esta investigación, que revela que casi la mitad de los residentes al caminar valora positivamente la presencia de comercio local, como son panaderías, 
Figura 4.

Uso de Suelo y caminabilidad.

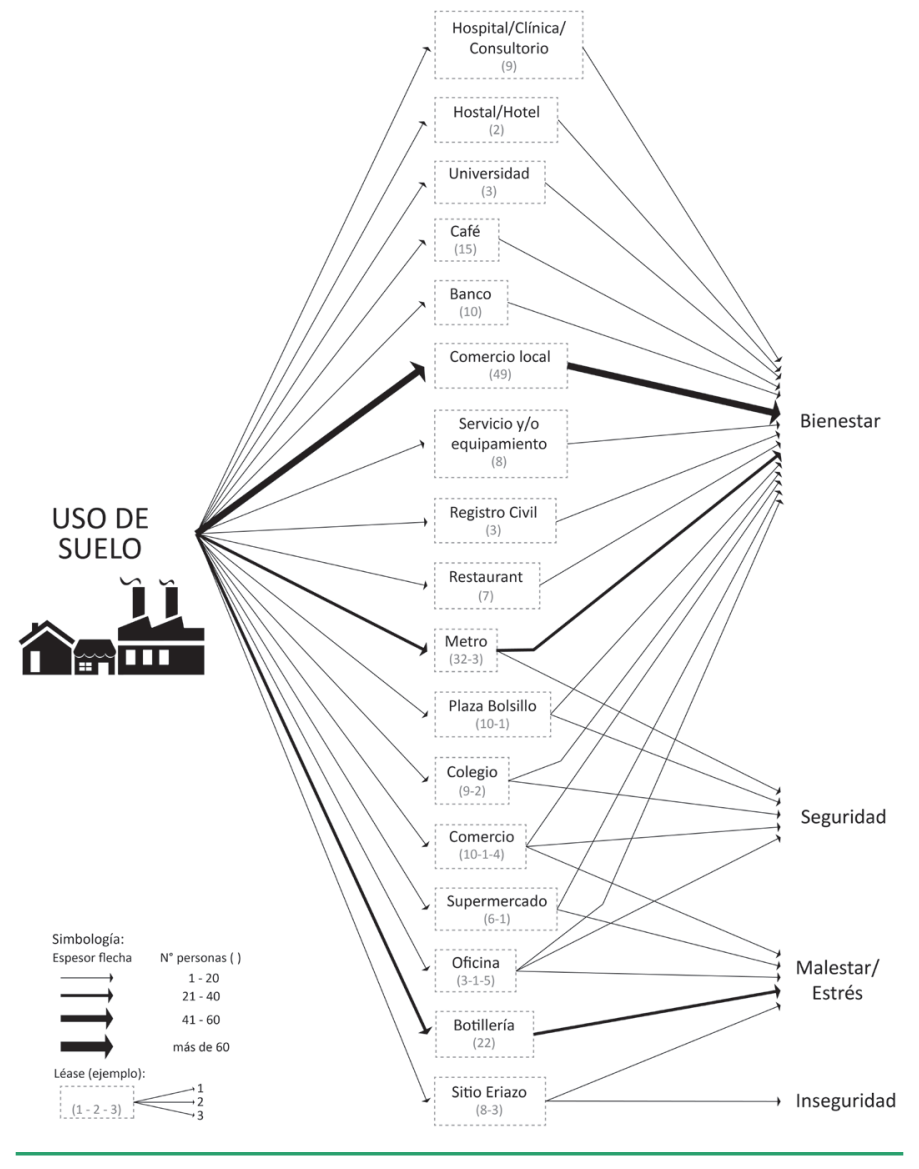

Fuente: Elaboración propia.

cafés, verdulerías, etc. (Figura 4). Como relataba un residente de 49 años (barrio Metro Colón):

Lo bueno en el barrio que muchos edificios han considerado locales comerciales abajo. Antiguamente este sector era muy poco servido, o sea tú tenías que desplazarte mucho para ir a comprar, en cambio ahora tú tienes un café cerca, tienes negocio cerca, eso ha mejorado bastante [...]. Ahora está lleno, aquí hay dos, tres cafés juntos uno al lado del otro, y a la hora que uno camina, si se quiere se toma un café, o sea uno ve mucha gente tomando café o en reuniones de trabajo, cosas por el estilo.

En este sentido, muchos residentes apreciaban que el comercio local activaba el espacio público adyacente a la vereda, otorgando vida y supervisión pasiva a la calle (Jacobs, 1961), además de proveer la venta de bienes y servicios de uso diario en la cercanía de sus hogares. Otros usos que fueron percibidos de forma positiva por los residentes fueron servicios de salud, servicios educacionales, bancos y el Metro. Contrariamente, las botillerías y los sitios eriazos generaban estrés e inseguridad en muchos residentes.

\section{El árbol}

El árbol destacó como elemento clave para una experiencia positiva del caminar, siendo mencionado 143 veces por los caminantes. El árbol en la calle puede localizarse en veredas, antejardines, platabandas, bandejones y/o plazas adyacentes. Cabe indicar, que los árboles y las áreas verdes generan múltiples beneficios ambientales y sociales. Por un lado, las áreas verdes producen sombras, menores temperaturas, mayor humedad ambiental, filtran polvo y son hábitat de fauna (Wittig, 1993). Por otro lado, son importantes lugares de recreación y contacto social. 


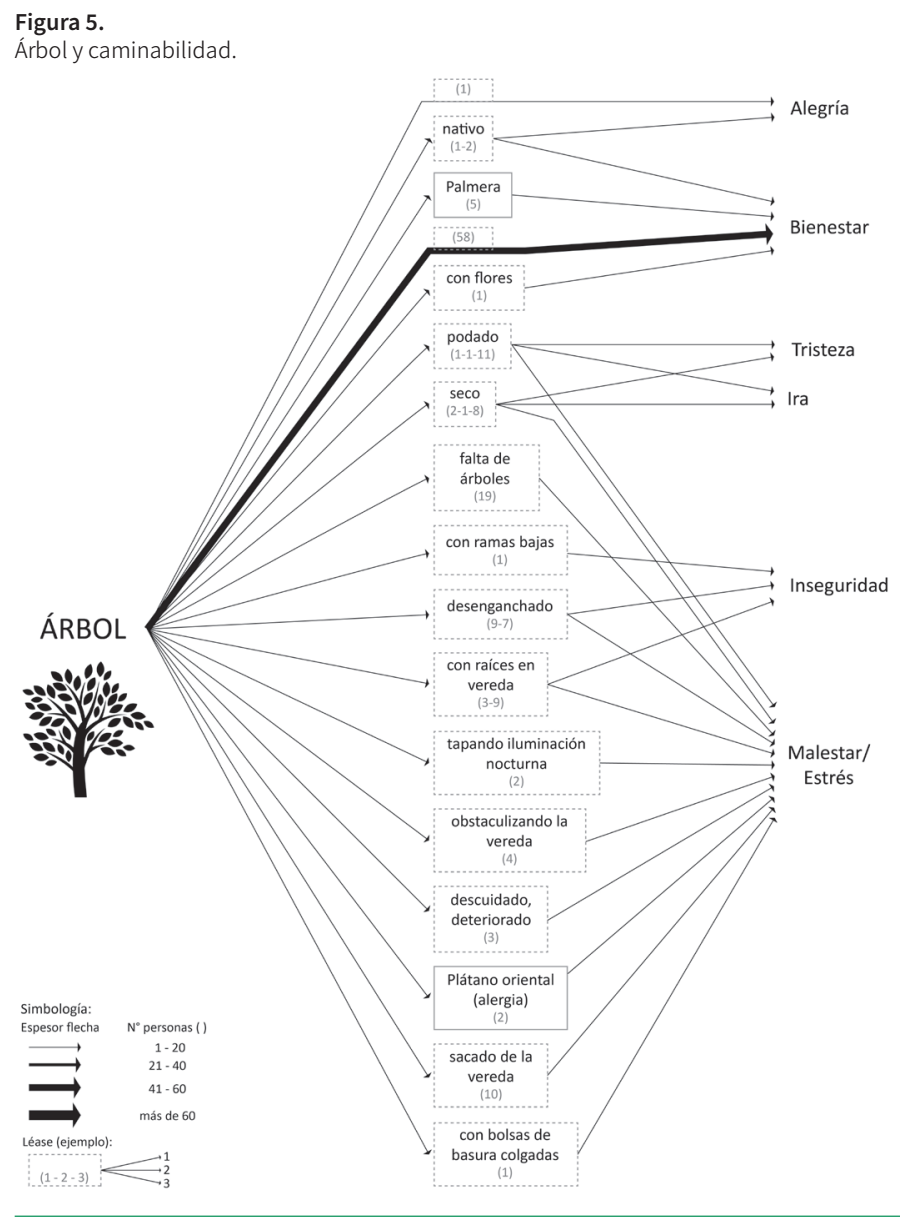

Fuente: Elaboración propia.

Notablemente, más de la mitad de los residentes expresaron que los árboles en las calles les generaban bienestar, y en algunos casos, incluso alegría (Figura 5). Los caminantes destacaban entre otros atributos positivos del árbol su sombra, sus colores y flores. Como narraba una mujer de 23 años (barrio metro Colón):

Me es cómodo, o sea relajante caminar por lugares donde hay mucho árbol, como acá... se notan muchos árboles, que se ve sombra, que corre viento, es agradable especialmente a esta hora, donde en otros lugares, quizás, el sol está como matando, pero acá no, es agradable caminar, corre viento.

Sin embargo, en determinadas condiciones los árboles causaban desagrado y/o inseguridad al caminar, como, por ejemplo, cuando estaban descuidados, deteriorados, con raíces en la vereda y/o desenganchados. Asimismo, algunas personas declararon que los árboles podados y secos les generaban tristeza e ira.
Cabe destacar, que la mitad de los caminantes de barrios de bajos ingresos (San Alberto Hurtado y Ecuador) resaltaron la falta de árboles en sus calles, expresando que la ausencia de árboles era estresante para su caminar. Preocupantemente, esto fue mencionado cuatro veces más en los barrios de ingresos bajos que en los barrios de ingresos medios y altos. Esto refleja claramente las desigualdades territoriales en Santiago, manifestadas también en la provisión de árboles y áreas verdes en el espacio público. Al respecto, estudios recientes muestran que la macrozona central de Chile es la que tiene mayor desigualdad en el acceso a áreas verdes, con comunas de altos ingresos como Las Condes o Providencia con 9,7 m2 o 5,1 m2 de áreas verdes por habitante, mientras que comunas de bajos ingresos como La Pintana o Maipú solo tienen 3,6 m2/ hab y 3,5 m2/hab respectivamente (Reyes-Päcke, De la Barrera, Bobbs, Spotorno y Pavez, 2014). 
Figura 6.

Áreas verdes y caminabilidad.

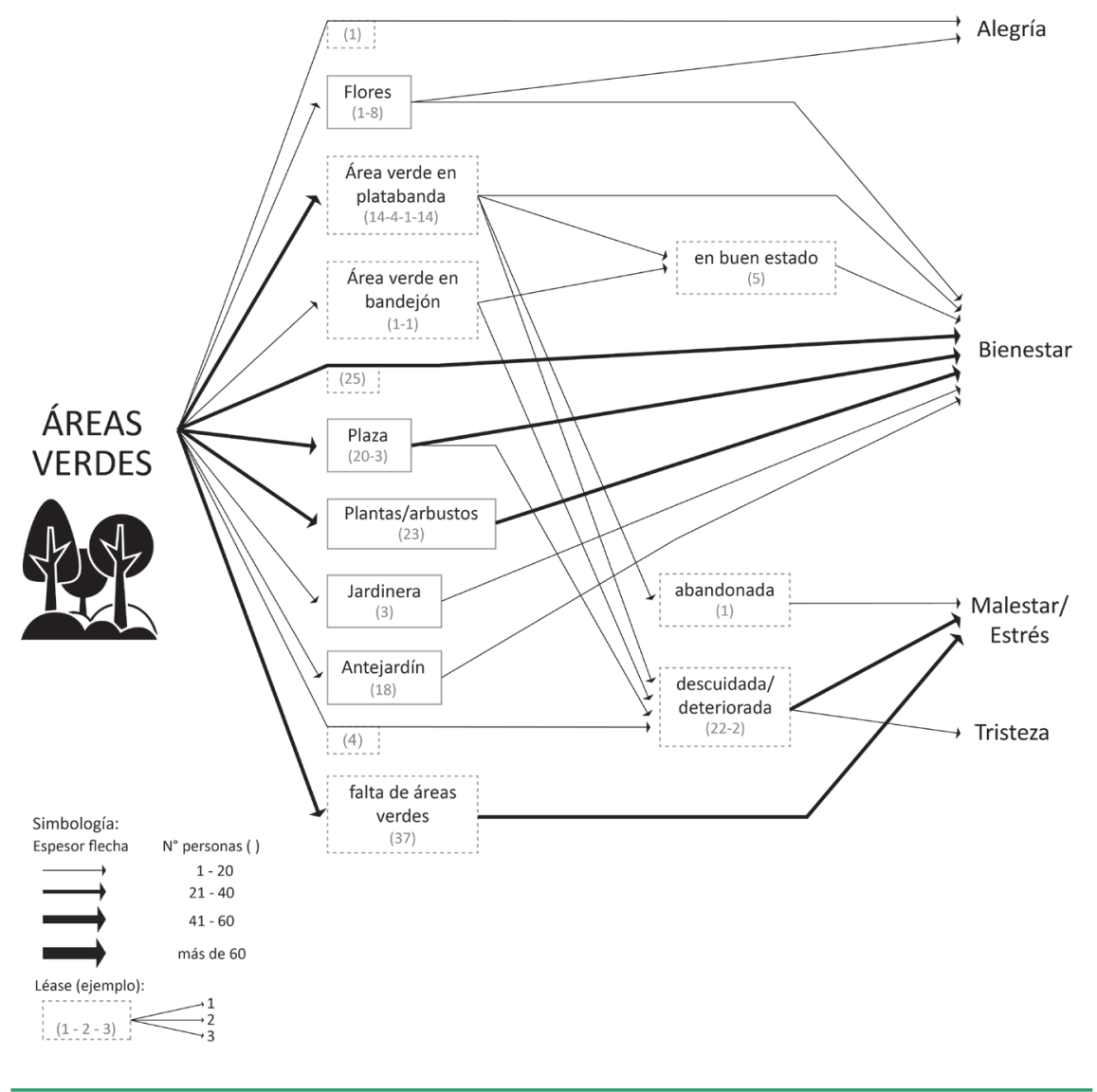

Fuente: Elaboración propia.

\section{Las áreas verdes}

No solamente los árboles, sino también las áreas verdes en general fueron nombradas por los residentes como elementos del paisaje urbano que causaban bienestar al caminar, siendo mencionadas en total 112 veces por los caminantes. Así, las plantas y arbustos, las áreas verdes en platabandas y bandejones, las jardineras, las flores, los antejardines y las plazas fueron señaladas como elementos que afectaban positivamente la caminata (Figura 6).

Un aspecto alarmante, es que todos los residentes de barrios de bajos ingresos resaltaron la falta de áreas verdes en sus vecindarios, indicando que la ausencia de áreas verdes en las calles era estresante para su caminar. Esto fue declarado cuatro veces más en los barrios de ingresos bajos que en los barrios de ingresos medios y altos, reflejando nuevamente las fuertes inequidades en el espacio público urbano de
Santiago. En palabras de una mujer de 34 años (barrio Metro San Alberto Hurtado):

No sé si por parte de algún ministerio, la municipalidad, no sé, pero no hay veredas, y las veredas que hay son muy malas, o sea, un abuelito fácilmente tropieza, las calles son malas, ahora las están arreglando por las constructoras, que se ha expandido de forma increíble, pero las veredas, por acá nada, nada... no hay árboles, no hay plaza, eso [...]. Entonces este sector es muy abandonado, no hay plaza para los niños. Estas máquinas para hacer ejercicio si tú quieres venir, en la noche aquí hay cabros tomando cerveza, piteando marihuana, entonces tampoco sirve. Eso poh, este sector es como abandonado [...]. Acá había árboles, viejitos los árboles, y con la constructora arreglaron aquí y pusieron esta palmeta, pero extirparon todos los árboles, no le preguntaron a ningún vecino (já) no sé, no sé si se hará eso, y dejaron todo esto en una zona 
Figura 7.

Cruces y caminabilidad.

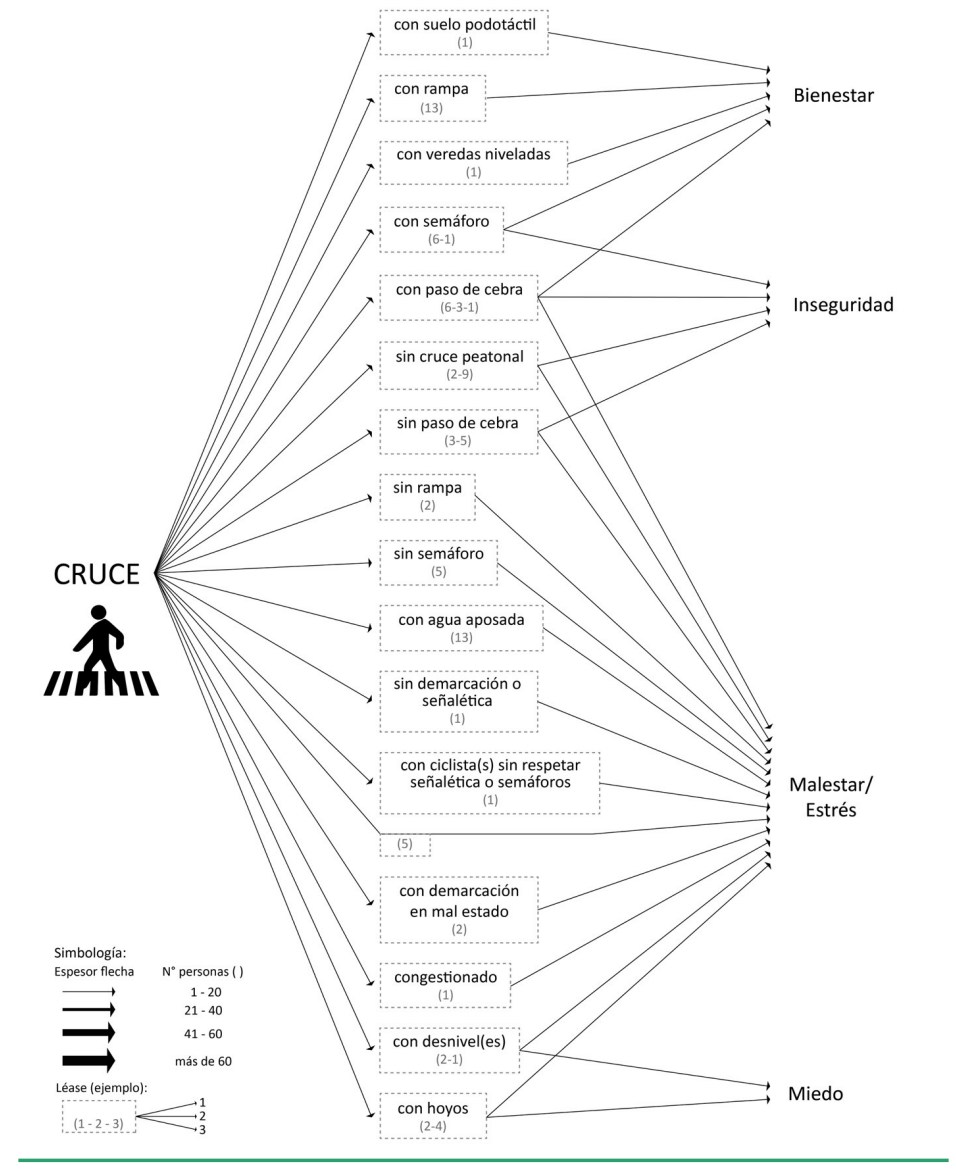

Fuente: Elaboración propia.

seca, desierta, como ustedes pueden ver no hay árboles, no hay nada [. . .]. Nada poh, las veredas ahora están parejita, pero es fome poh, sería rico sentarse bajo un arbolito.

\section{Los cruces}

Los cruces fueron percibidos por más de un tercio de los residentes como elementos de peligro y conflicto al caminar, siendo mencionados en total 58 veces. Cabe señalar, que en los cruces deben interactuar todos los usuarios de la calle, es decir, peatones, ciclistas y conductores de vehículos motorizados privados y públicos, siendo lugares de frecuentes accidentes, algunos incluso mortales. La Ordenanza General de Urbanismo y Construcciones (OGUC) no regula cómo debiesen ser diseñados los cruces entre calles, por lo que el diseño de intersecciones es definido habitualmente por manuales como Recomendaciones para el diseño de elementos de Vialidad Urbana, REDEVU (Ministerio de
Vivienda y Urbanismo, 2009), que prioriza el movimiento expedito de automóviles por sobre el peatón. Si bien los accidentes mortales de peatones han disminuido de un 36\% entre 2002 y 2018 (Conaset, 2017), la falta de progreso en la generación de cruces más seguros, está constituyéndose en una barrera para el potenciamiento de la caminata en Chile.

Según los caminantes, el principal problema fueron los cruces que no contaban con facilidades para que los peatones puedan cruzar de forma segura (Figura 7). Así, cruces sin semáforos y sin paso de cebra provocaban estrés, inseguridad y miedo en los caminantes. También la falta de rampas en los cruces fue mencionada como negativa por los caminantes. Otros problemas eran cruces mal demarcados (o sin demarcación o señalética alguna), congestionados, y con desniveles y/o hoyos. Más aún, incluso cruces con pasos de cebra generaban estrés e inseguridad en varios caminantes, siendo el cruce per se un elemento de conflicto al caminar. En efecto, el cruce 


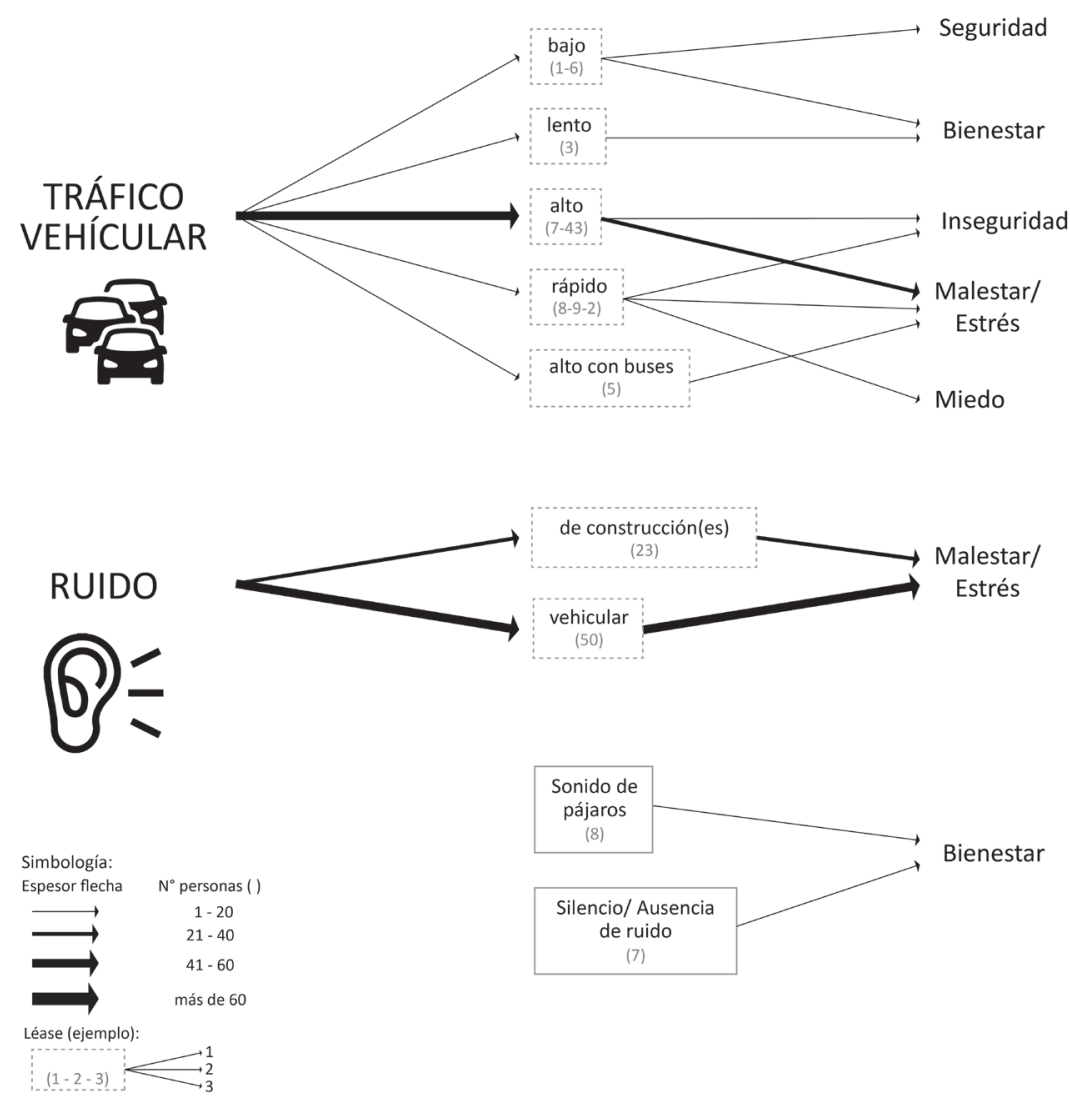

Fuente: Elaboración propia

obliga al caminante a un contacto más directo con los vehículos motorizados, siendo evidentemente el peatón el usuario más vulnerabilizado y discriminado, más aún en un contexto en que las reglas del tránsito muchas veces no son respetadas por automóviles y buses. Cabe señalar, que especialmente para los adultos mayores y mujeres con niños, los cruces eran puntos que severamente dificultaban su caminata, y que generaban miedo ante un posible accidente con un vehículo motorizado. Como señalaba un hombre de 40 años (barrio Metro San Alberto Hurtado):

Esta vereda, o sea, este paso de cebra el $80 \%$ de los automovilistas yo creo que no lo respetan... la gente tiene que esperar, incluso con niños tienen que esperar que se den cuenta de que están pasando personas, o que están esperando cruzar. Yo he visto bastante ¿cómo se llama? Situaciones peligrosas acá cuando la gente solamente se tira y se producen las frenadas fuerte, cuando están chillando los neumáticos por las frenadas.
La reciente reducción de la velocidad máxima en Chile en zonas urbanas desde $60 \mathrm{~km} /$ hora a $50 \mathrm{~km} /$ hora representa un avance para la seguridad vial de las personas. Sin embargo, para que estas medidas se hagan efectivas es necesario una mayor fiscalización, un asunto que topa con restricciones normativas que se encuentran actualmente en tramitación en el Congreso de Chile, así como una mayor disponibilidad de recursos para fiscalizar.

Cabe señalar, que otro problema mencionado por los residentes fueron los ciclistas que no respetaban la señalética o los semáforos en los cruces, mostrándose el conflicto entre peatones y ciclistas no solamente en las veredas, sino también en los cruces. Finalmente, como únicas características positivas, los caminantes señalaron las veredas niveladas y con rampas, así como el suelo podotáctil en unos pocos cruces. 


\section{El tráfico vehicular y el ruido}

El tráfico vehicular y el ruido fueron destacados por los residentes como unos de los principales elementos que generaban estrés al caminar (mencionados 84 y 50 veces respectivamente). Llama la atención, que casi la mitad de todas las personas -en los seis barrios- expresó que el ruido vehicular les provocaba mucha molestia mientras caminaba (Figura 8). Estudios recientes han mostrado que la presencia de ruido vehicular genera estrés (Basner et al., 2014), afectando negativamente la calidad de vida en general (Seidman \& Standring, 2010), e incluso acelerando la velocidad con que se camina (Franěk, Režný \& Cabal, 2018). En las palabras de un residente de 70 años (barrio Metro Francisco Bilbao):

En esta parte sí, incluso, los ruidos y el paso de los autos y buses, todo eso hace que sea más, no sé cómo decirlo, más difícil poder realmente caminar, ¿no? No es sumamente placentero como en las calles residenciales, en las calles uno encuentra tranquilidad y eso, y dan ganas de caminar y mirar un poco, mientras que acá no, acá es terrible el ruido...

En contraste, varios caminantes señalaron que el sonido de pájaros y los espacios urbanos silenciosos les generaban bienestar al caminar, destacándose el silencio como un elemento clave para una caminata de "restauración", es decir, una caminata que permitía un estado de relajo mientras se caminaba.

Otro elemento que claramente dificultaba la caminata en los seis barrios pericentrales era el tráfico vehicular motorizado. Así, casi la mitad de los caminantes declaró que el tráfico vehicular alto y/o rápido provocaba estrés, e incluso inseguridad y miedo en algunos caminantes, en especial en los cruces, y particularmente en el caso de las mujeres con niños y los adultos mayores. De hecho, la experiencia de la caminata en todos los barrios claramente empeoraba a medida que los residentes se acercaban a las calles principales, donde aumentaba considerablemente el tráfico y ruido vehicular.

\section{Conclusiones}

Las entrevistas revelaron claramente qué elementos del entorno construido facilitan y, en contraste, qué elementos inhiben la caminata en barrios pericentrales del Gran Santiago. Así, según los propios residentes, la presencia de veredas anchas y en buen estado, árboles y uso mixto facilita la caminata. En contraste, factores que inhiben la caminata son veredas angostas y en mal estado, falta de árboles y áreas verdes, los cruces y, en especial, el tráfico motorizado y ruido vehicular.

Interesantemente, el impacto que generaba el paisaje urbano en la caminata no dependía solamente de la presencia de ciertos elementos del paisaje urbano, sino también de las características de estos elementos. Por ejemplo, el árbol era percibida de forma muy positiva para la caminata, pero generaba ira y tristeza cuando estaba seco o podado. No obstante, algunos elementos fueron percibidos como negativos per se como son el ruido, el tráfico vehicular alto y rápido, y los cruces.

Las calles constituyen, en general, alrededor de un 20-30\% de la superficie de las ciudades (Herrmann-Lunecke, 2006). Es decir, son un espacio público fundamental, el cual debe recibir más atención en términos de planificación y diseño urbano, en particular respecto al peatón. En base a la presente investigación, se pueden extraer una serie de recomendaciones para el diseño de calles en barrios pericentrales que promuevan una caminata.

\section{Recomendaciones para promover la caminata}

En primer lugar, deben fomentarse las veredas anchas. En el marco de este estudio, los caminantes declaraban que las veredas anchas les generaban bienestar, mientras que las veredas angostas producían estrés. En Chile, desafortunadamente, muchas veredas están subdimensionadas, presentando en hartos casos un ancho de no más de 1,2 m (en otros casos las aceras ni siquiera existen o no están pavimentadas). En contraposición, las calzadas de las calles están sobredimensionadas (7 $\mathrm{m}$ ), independiente del tipo de calle y la velocidad máxima permitida. En este contexto, es urgente revisar 
los anchos mínimos viales establecidos en la OGUC (1,2 $\mathrm{m}$ para aceras en zonas residenciales y $2 \mathrm{~m}$ en zonas comerciales), en el caso de nuevas urbanizaciones. A modo referencial, se establece, por ejemplo, en Alemania para las veredas un ancho mínimo de $2,5 \mathrm{~m}$ en áreas residenciales (Herrmann-Lunecke, 2016), lo que permite el paso de dos sillas de rueda o coches de niños. Por otro lado, en el caso de las urbanizaciones existentes, donde no siempre es posible cumplir con los mínimos exigidos de calzada y aceras, es necesario que la OGUC priorice los modos más sustentables (caminata y bicicleta), en desmedro del automóvil, asignando más espacio vial a la caminata. Esta visión es habitualmente representada por la "pirámide invertida de la movilidad" y ha sido incorporada por municipios como Providencia, en Santiago, en la planificación y diseño vial. Más aún, en los últimos diez años el Municipio de Santiago centro ha emprendido con gran éxito, la transformación de sus calles basado en la pirámide invertida de la movilidad. Asimismo, se requiere de veredas bien mantenidas, continuas, con rampas y sin obstáculos. Los caminantes resaltaban que las veredas con hoyos, desniveles, baldosas sueltas, basura, autos o ciclos estacionados generaban estrés, inseguridad y miedo, en especial para la tercera edad y personas en situación de discapacidad. Para ello es necesario aumentar sustantivamente la inversión destinada a la caminata en Chile, que actualmente representa solo el $2.78 \%$ de lo que se invierte en caminos (Iglesias, Giraldez, Tiznado-Aitken, \& Muñoz, 2019).

Un elemento clave para el fomento de una caminata de bienestar es el árbol. Por lo tanto, la planificación y el diseño urbano deben promover las veredas verdes. Las veredas con árboles y plantas (en veredones, antejardines, etc.) generan bienestar al caminar, mientras que la falta de árboles y áreas verdes produce desagrado y estrés, según los caminantes. Para el caso de Santiago, la falta de árboles es especialmente crítica en comunas de menores ingresos. En un detallado estudio sobre arbolado urbano, Hernández (2008) mostró que existen diferencias muy importantes tanto en la cantidad de árboles, como en la existencia de inventarios de arbolado urbano, en los planes de manejo y en el presupuesto asignado para riego de éstos, entre comunas de mayores y menores ingresos de Santiago. Las altas diferencias climáticas chilenas sugieren que la aproximación al arbolado urbano debiese acoger las características de las tres macrozonas chilenas, norte, centro y sur, toda vez que tanto la disponibilidad de agua (cada vez menor por la megasequía que afecta a la macrozona central desde hace diez años), como los recursos involucrados para mantener el arbolado urbano difieren enormemente en las tres zonas (ReyesPäcke et al., 2014).

Además, se debería promover el uso mixto en los barrios, en particular de comercio local, el cual contribuye a la vitalidad y seguridad de las calles. Asimismo, se deben proveer veredas con adecuada iluminación nocturna para peatones, para así aumentar la seguridad.

En el marco de este estudio, ciertas características como, por ejemplo, lo "descuidado", "deteriorado" y "abandonado" siempre conllevaban a una percepción negativa, incluso en el caso de elementos que normalmente eran percibidos de forma muy positiva, como árboles y áreas verdes. Más aún, "deteriorado" y "descuidado" fueron las características más mencionadas durante las entrevistas que conllevaban a una experiencia negativa del caminar, en especial en el caso de los barrios más vulnerables. Es decir, para mejorar los entornos de movilidad peatonal no solamente deben proveerse ciertos elementos clave para la infraestructura física peatonal -como son veredas anchas y árboles- también éstos deben ser mantenidos y cuidados por los municipios y la misma comunidad. Esto resulta especialmente importante en sectores de menores ingresos, donde el deterioro de veredas y la falta de áreas verdes son alarmantes, reflejando la inequidad territorial de Santiago.

También, se debe prestar mayor atención al diseño de cruces seguros y amables para el peatón. Según los residentes, los cruces les generaban estrés, inseguridad e incluso miedo, e inhibían la caminata, en particular para peatones de la tercera edad, mujeres, niños y personas en situación de discapacidad. Por lo tanto, resulta fundamental diseñar cruces con rampas peatonales, cruces nivelados, cruces con pasos de cebra y/o con 
semáforos de tiempos más largos para peatones, entre otros. Esto requiere modificaciones sustantivas del manual REDEVU (Ministerio de Vivienda y Urbanismo, 2009) hacia marcos normativos más respetuosos de las necesidades de los peatones. Cabe señalar que el REDEVU, a pesar de solo ser un manual de recomendaciones, es usualmente exigido por las autoridades chilenas a cargo de visar el diseño vial. Al respecto, recientes recomendaciones sobre el diseño urbano vial aplicadas en contextos cercanos como la ciudad de Buenos Aires (Buenos Aires Ciudad, 2015), podrían ser empleados para la pacificación de los cruces de calles en Chile.

Finalmente, resulta primordial reducir la cantidad de automóviles y disminuir la velocidad del transporte motorizado en las calles, dado que genera estrés e inseguridad al peatón e inhibe la caminata. Esto ayudaría además a disminuir el ruido vehicular, que fue señalado por los residentes como un factor principal de estrés mientras caminaban por sus barrios. En este contexto, se requiere avanzar tanto en la puesta en marcha de nuevas normativas, que disminuyan la velocidad máxima en zonas urbanas, así como en la fiscalización de estas normativas. Con respecto a la velocidad de circulación en zonas urbanas, ésta fue disminuida en el año 2019 de 60 a 50 km/hora, una disminución positiva, aunque insuficiente para mejorar la calidad de vida urbana. Resulta urgente avanzar en la disminución de las velocidades máximas urbanas, cuyas consecuencias en el número de accidentes fatales están bien documentadas (Friedman, Hedeker \& Richter, 2009; Hydén, 2000), avanzando hacia estándares como los que hoy se están aplicando en países como Francia o Alemania, que mantienen velocidades máximas de $30 \mathrm{~km}$ /hora en la mayoría de sus áreas residenciales. Así, las recomendaciones anteriores deben traducirse en el diseño de nuevas tipologías de calles urbanas como podrían ser, por ejemplo, versiones locales de "calles completas" y "calles vivas", las cuales otorguen la misma importancia a todos los usuarios viales, e incluso prioridad a peatones y ciclistas. Promover la caminata requiere además de una serie de mejoras institucionales y de gobernanza como son, por ejemplo, un incremento en el gasto público en veredas, y una mayor coordinación sectorial y coordinación entre el gobierno nacional y local para planificar, diseñar e implementar calles más amables para el peatón. Asimismo, se debe consultar e involucrar más a la ciudadanía -en especial a mujeres, adultos mayores, niños y personas en situación de discapacidad-en el diseño de calles.

Lograr lo anterior requiere también de una nueva gobernanza urbana, aspecto que ha sido insistentemente señalado por urbanistas en los últimos veinte años (Heinrichs, Nuissl \& Rodríguez, 2009; Valenzuela-Van Treek \& Toledo-Alarcón, 2017). Se requiere pasar de una lógica de inversión y preocupación sectorial, hacia una de colaboración entre los diferentes ministerios relacionados con la ciudad y los municipios, en torno a la movilidad y el diseño urbano. A nivel local, existen buenos ejemplos de lo anterior, como la Mesa Técnica Multidisciplinar que implementó la Municipalidad de Providencia, que coordina la labor de las distintas divisiones municipales relacionadas con la planificación urbana.

Desafortunadamente, en Chile el diseño de calles se enfoca en el transporte motorizado, en desmedro de otros usuarios como los peatones, y en especial, los peatones más vulnerabilizados. Como resultado, las calles y los espacios públicos peatonales en Chile carecen de un apropiado diseño y presentan una serie de problemas en su entorno físico-espacial (HerrmannLunecke 2016, 2006), reproduciendo inequidades (autos/ peatones, hombres/mujeres, etc.). En consecuencia, se requiere en Chile una nueva concepción de la calle, donde se prioricen los modos de transporte más sustentables, es decir, al peatón, ciclista y transporte público. Finalmente, faltan en Chile más estudios detallados de percepción que analicen como distintos grupos de peatones perciben su entorno urbano y cuáles son los atributos del entorno construido que promueven o inhiben la caminata, los que podrían constituir un aporte significativo para la arquitectura y el diseño urbano en Chile, y la construcción de barrios más caminables, inclusivos y saludables. 


\section{Referencias bibliográficas}

Adkins, A., Makarewicz, C., Scanze, M., Ingram, M., \& Luhr, G. (2017). Contextualizing walkability: do relationships between built environments and walking vary by socioeconomic context? Journal of the American Planning Association, 83(3), 296-314. https://doi.org/10.1080/01 944363.2017.1322527

Allen, H., Cárdenas, G., Pereyra, L. \& Sagaris, L. (2019). Ella se mueve segura. Un estudio sobre la seguridad personal de las mujeres y el transporte público en tres ciudades de América Latina. Caracas: CAFy FIA Foundation. Recuperado de http://scioteca.caf.com/handle/123456789/1405

Arellana, J., Saltarín, M., Larrañaga, M., Alvarez, A. \& Henao, C. (2019). Urban walkability considering pedestrians' perceptions of the built environment: a 10-year review and a case study in a medium-sized city in Latin America. Transport Reviews. https://doi.org/10.1080/01441647 .2019 .1703842

Basner, M., Babisch, W., Davis, A., Brink, M., Clark, C., Janssen, S. \& Stansfeld, S. (2014). Auditory and non-auditory effects of noise on health. The Lancet, 383(9925), 1325-32.

Berding, U., Kulinski, O.\&Selle, K. (2003).Städte als Standortfaktor: Öffentlicher Raum. Bonn: Bundesamt für Bauwesen und Raumordnung.

Bopp, M., Kaczynski, A.T. \& Campbel, M.E. (2013). Health-Related Factors Associated with Mode of Travel to Work. Journal of Environmental and Public Health, 2013. 1-9. https://doi. org/10.1155/2013/242383

Brown, B., Werner, C., Amburgey, J.W. \& Szalay, C. (2007). Walkable Route Perceptions and Physical Features Converging Evidence forEn Route Walking Experiences. Environmentand Behavior, 39(1), 34-61. https://doi.org/10.1177/0013916506295569

BuenosAires Ciudad. (2015). Manual deDiseño Urbano. Recuperado dehttps://www.buenosaires.gob.ar/sites/gcaba/files/ manual_de_diseno_urbano_-_gcba_4.pdf
Cain, K., Geremia, C.M., Conway, T.L., Frank, L., Chapman, J., Fox, E., Timperio, A., Veitch, J., van Dyck, D., Reis, R., Augusto, A., Cerin, E., Mellecker, R., Queralt, A., MolinaGarcía, J. \& Sallis, J. (2018). International Journal of Behavior and Nutrition and Physical Activity (15), 19. https://doi.org/10.1186/s12966-018-0650-z

Cámara Chilena de la Construcción. (2013). Estudio de densificación: Identificación del potencial de densificación entorno de la red de metro de la ciudad de Santiago. Observatorio UC, P. Contrucci. Recuperado dehttp://www.cchc.cl/wp-content/ uploads/2013/05/Estudio-de-Densificación-PABLOCONTRUCCI.pdf

Center for Disease Control and Prevention. (2012). Vital signs: walking among adults, United States, 2005 and 2010. Morbidity and Mortality Weekly Report (MMWR), 61(31), 595-601. Recuperado dehttps://www.cdc.gov/mmwr/preview/ mmwrhtml/mm6131a4.htm

Cervero, R. \& Kockelman, K. (1997). Travel Demand and the 3Ds: density, diversity and design. Transportation Research Part D: Transport and Environment, 3(2), 199-219. https://doi. org/10.1016/s1361-9209(97)00009-6

Conaset. (2017). Observatorio de Datos. Recuperado de https://www.conaset.cl/programa/observatorio-datosestadistica/

Charmaz, K. (2006). Constructing Grounded Theory. A practical guide through qualitative analysis. London: SAGE.

Clifton, K.J., Livi, A. \& Rodríguez, D. (2007). The Development and Testing of an Audit for the Pedestrian Environment. Landscape and Urban Planning, 80(1-2), 95-110. https:// doi.org/10.1016/j.landurbplan.2006.06.008

Damasio, A. (1994). Descartes' Error, Emotion, Reason and the Human Brain. New York: Putnam.

Dovey, K., \& Pafka, E. (2020). What is walkability? The urban DMA. Urban Studies, 57(1), 93-108. https://doi. org/10.1177/0042098018819727 
Ewing, R. \& Cervero, R. (2001). Travel and the built environment: Asynthesis. Transportation Research Record 1780(1), 87-114.

Ewing, R. \& Cervero, R. (2010). Travel and the built environment: A meta-analysis. Journal of the American planning association, 76(3), 265-294. https://doi. org/10.1080/01944361003766766

Figueroa, C. y Forray, R. (2015). Movilidad femenina: los reveses de la utopía socio-espacial en las poblaciones de Santiago de Chile. Revista de Estudios Sociales, (54), 52-67. https:// doi.org/10.7440/res54.2015.04

Figueroa, C., Hodgson, F., Mullen, C. \& Timms, P. (2018). Creating inequality in accessibility: The relationships between public transport and social housing policy in deprived areas of Santiago de Chile. Journal of Transport Geography $67,102-109$

Figueroa, C., Hodgson, F., Mullen, C. \& Timms, P. (2019). Walking through deprived neighbourhoods: meanings and constructions behind the attributes of the built environment. Travel Behaviour and Society, 16, 171-181.

Forsyth, A. (2015). What is a walkable place? The walkability debate in urban design. Urban Design International, 20(4), 274-292. https://doi.org/10.1057/udi.2015.22

Franěk M.,Režný L., D., \& Cabal J. (2018). Effect of Traffic Noise and Relaxations Sounds on Pedestrian Walking Speed. International Journal of Research on Public Health 15(4). https://doi.org.10.3390/ijerph15040752

Friedman, L., Hedeker, D. \& Richter, E. (2009). Long-Term Effects of Repealing the National Maximum Speed Limit in the United States. American Journal of Public Health 99(9): 1626-1631. https://doi.org/10.2105/AJPH.2008.153726

Gaete-Reyes, M. (2017). Discapacidad y hábitat residencial: una emergencia en Chile. En Imilan, W; Larenas, J. Carrasco, G, \& Rivera, S. (Eds.). ¿Hacia dónde va la vivienda en Chile?: nuevos desafíosenel hábitatresidencial, pp.281-295. Santiago deChile: INVI, MINVU, Adrede.
Gehl, J. \& Gemzoe, L. (1996). Public Spaces. Public Life. Copenhagen, Denmark: The Danish Architectural Press and Royal Danish Academy of Fine Arts, School of Architectural Publishers.

Golkar, K. (2008). Conceptual evolution of urban visual environment; from cosmetic approach through to sustainable approach. Environmental sciences 5 (4), 95-113.

Hanibuchi, T., Nakaya, T. \& Inoue, S. (2019). Virtual audits of streetscapes by crowdworkers. Health \& Place, 59, 102203. https://doi.org/10.1016/j.healthplace.2019.102203

Handy, S.L., Boarnet, M.G., Ewing, R. \& Killingsworth, R.E. (2002). How the built environment affects physical activity: views from urban planning. American journal of preventive medicine, 23(2), 64-73.

Heath, G.W., Brownson, R.C., Kruger, J., Miles, R., Powell, K.E. \& Ramsey, L.T. (2006). The effectiveness of urban design and land use and transport policies and practices to increase physical activity: a systematic review. Journal of physical activity and health, 3(s1), S55-S76.

Heinrichs, D., Nuissl, H. \& Rodríguez, C. (2009). Dispersión urbana y nuevos desafíos para la gobernanza (metropolitana) en América Latina: el caso de Santiago de Chile. EURE 35 (104), 29-46. https://doi.org/10.4067/S0250-71612009000100002.

Hernández, J. (2008). La situación del arbolado urbano en Santiago. Revista de Urbanismo, 18.

Herrmann-Lunecke, M. G. \& van Klaveren, F. (2013). ¿Cómo densificar? Problemas y desafíos de las tipologías de densificación en la ciudad de Santiago, Chile. Revista 180 (31), 38-43. https://dx.doi.org/10.32995/rev180. Num-31.(2013).art-73.WOS

Herrmann-Lunecke, M. G., Mora, R. \& Sagaris, L. (2020). Persistence of walking in Chile: lessons for urban sustainability. Transport Reviews. https://doi.org.10. $\underline{1080 / 01441647.2020 .1712494}$ 
Herrmann-Lunecke, M. G., Mora, R. \& Monsalve, S. (2020). Entornos de movilidad peatonal que fomentan la caminata: un análisis en barrios del Gran Santiago. Intersecciones 2018. En: Encinas, F., Arze, G., \& Fuentes, P. (eds). Intersecciones 2018. Ediciones ARQ: Santiago, Chile.

Herrmann-Lunecke, M. G. (2006). Instrumente zur Planung und Gestaltung desöffentlichen Straßenraumes in Deutschland und deren Anwendungschancen in Chile. Berlín: TUB, FakultätVI Planen, Bauen, Umwelt(Herausgeber), Universitätsbibliothek TUB, Digitales Rep. Recuperada en http://opus.kobv.de/ tuberlin/volltexte/2005/1174

Herrmann-Lunecke, M. G. (2016). Instrumentos de planificación y diseño urbano para promover al peatón en las ciudades. Un estudio comparado entre Chile y Alemania. Revista Urbano (34), 48-57. https://doi.org/1022320/0718360 7.2016.19.34.5

Hill, J., Wyatt, H., Reed, G., \& Peters, J. (2003). Obesity and the environment: Where do we go from here? Science 299(5608), 853-855. https://doi.org/10.1126/science.1079857

Hillier, B. (1996). Space Is the Machine A Configurational Theory of Architecture. Cambridge University Press, Cambridge.

Hydén, Ch. (2020). Speed in a high-speed society. International Journal of Injury Control and Safety Promotion 27(1), 44-50. https://doi.org/10.1080/17457300.2019.1680566

IDE. (2017). Catálogo Nacional de Información Geoespacial. Santiago, Chile: IDE.

Iglesias, V., Giraldez, F., Tiznado-Aitken, I. \& Muñoz, J. C. (2019). How uneven is the urban mobility playing field? Inequalities among socioeconomic groups in Santiago De Chile. Transportation Research Record, 2676(11), 69-70. https://doi.org/10.1177/0361198119849588

INE. (2002). Censo Nacional de Población y Vivienda. Santiago, Chile: INE.
Inzulza-Contardo, J. (2016). Contemporary Latin American gentrification? Young urban professionals discovering historic neighbourhoods. Urban Geography, 37(8), 11951214. https://doi.org/10.1080/02723638.2016.1147754

Jacobs, J. (1961). The Death and Life of Great American Cities. Michigan: Random House.

Jirón, P. e Imilán Ojeda, W. (2018). Moviendo los estudios urbanos. La movilidad como objeto de estudio o como enfoque para comprender la ciudad contemporánea. Quid, 16(10), 17-36.

Jirón, P. y Gómez, J. (2018). Interdependencia, cuidado y género desde las estrategias de movilidad en la ciudad de Santiago. Tempo Social, 30(2), 55-72. https://dx.doi. org/10.11606/0103-2070.ts.2018.142245

Jirón, P. (2013). Sustainable Urban Mobility in Latin America and the Caribbean. Thematic study for the Global Report on Human Settlements 2013. Recuperado en http:// www.unhabitat.org/grhs/2013

Kenyon, S., Lyons, G. \& Rafferty, J. (2002). Transport and social exclusion: Investigating the possibility of promoting inclusion through virtual mobility. Journal of Transport Geography 10(3), 207- 219. https://doi.org/10.1016/ s0966-6923(02)00012-1

Keshtkaran, R. (2019). Urban Lanscape: A review of key concepts and main purposes. International Journal of Development and Sustainability 8 (2), 141-168.

Krizek, K. J., Handy, S. L., \& Forsyth, A. (2009). Explaining Changes in Walking and Bicycling Behavior: Challenges for Transportation Research. Environment and Planning B: Planning and Design 36(4), 725-740. https://doi. org/10.1068/b34023

Leslie, E., Saelens, B., Frank, L., Owen, N., Bauman, A., Coffee, N. \& Graeme, H. (2005). Residents' perceptions of walkability attributesin objectively differentneighbourhoods: a pilotstudy. Health \& Place, 11(3), 227-236. https://doi.org/10.1016/j. healthplace.2004.05.005 
Loukaitou-Sideris, A., \& Ehrenfeucht, R. (2009). Sidewalks: Conflict and Negotiation over Public Spaces. Cambridge: The MIT Press.

Lynch, K. (1960). The image of the city. MIT press: Boston.

Maderuelo, J. (2010). El paisaje Urbano. Estudios Geográficos Vol. LXXI (269), 575-600. https://doi.org/10.3989/ estgeogr.201019

Ministerio de Vivienda y Urbanismo. (2009). REDEVU, Manual de Vialidad Urbana. MINVU: Santiago.

Ministerio de Vivienda y Urbanismo. (2014). Política Nacional de Desarrollo Urbano. Ciudades Sustentables y Calidad de Vida. MINVU: Santiago.

Mora, R., Greene, M. y Reyes, M. (2018). Uso y percepción del espacio público en dos barrios vulnerables. Revista AUS, (24), 53-60. https://doi.org/10.4206/aus.2018.n24-08

Mora R. y Zapata, I. (2004). Comercio, espacio público y gestión local: el caso de Providencia en Santiago de Chile. Revista de Urbanismo, 9, 29-48. https://doi.org/10.5354/0717$\underline{5051.2010 .5083}$

Morgan, A.L., Tobar, D.A., \& Snyder L. (2010). Walking toward a new me: the impact of prescribed walking 10,000 steps/day on physical and psychological well-being. Phys Act Health, 7(3), 299-307. https://doi.org/10.1123/jpah.7.3.299

Organización Mundial dela Salud. (2019).Age friendly Environments. Recuperado en https://www.who.int/ageing/age-friendlyenvironments/en/

Pavez Reyes, M. I. (2013). Un corredor verde entre cerros desde 1934, y las posibilidadesactuales desde un ejercicio académico de pregrado en Recoleta. Revista de Urbanismo, 29, 75-95. https://doi.org/10.5354/0717-5051.2013.30306

Paydar, M., Kamani-Fard, A. \& Etminami-Ghasrodashti, R. (2017). Perceived security of women in relation to their path choice toward sustainable neighborhood in Santiago, Chile. Cities, 60,289-300.https://doi.org/10.1016/j.cities.2016.10.002
Reyes-Päcke, S., De la Barrera, F., Bobbs, C., Spotorno, A. \& Pavez, C. (2014). Costos demantención delasáreas verdesurbanasen Chile. InformeFinal. Recuperadode http://observatoriodoc.colabora. minvu.cl/Documentos\%20compartidos/ESTUDIOS\%20 OBSERVATORIO/IFinal-Costoareas-verdes-PUC.pdf

Rodríguez, D. \& Joo, J. (2004). The relationship between nonmotorized mode choice and the local physical environment. Transportation Research PartD. Transport and Environment, 9(2), 51-173. https://doi.org/10.1016/j.trd.2003.11.001

Rossetti, T., Lobel, H., Rocco, V. \& Hurtubia, R. (2019). Explaining subjective perceptions of public spaces as a function of the built environment: A massive data approach. Landscape and Urban Planning, 181, 169-178. https:// doi.org/10.1016/j.landurbplan.2018.09.020

Saelens, B.E. \&Handy, S.L. (2008). Built environment correlates of walking: a review. Medicine and science in sports and exercise, 40(7 Suppl), S550-S566. https://doi.org/10.1249/ mss.0b013e31817c67a4

Sagaris, L. \& Tiznado-Aitken, I. (2020). Walking and gender equity: Insights from Santiago, Chile. En D. Oviedo Hernandez, N. Villamizar-Duarte \& A. Ardila Pinto (Eds.), Urban Mobility and Equity in Latin America. Emerald Books: London.

Sallis, J.F., Cain, K.L., Conway, T., Gavand, K., Millstein, R., Geremia, C., Frank, L., Saelens, B., Glanz, K. \& King, A. (2015). Is Your Neighborhood Designed to Support Physical Activity? A Brief Streetscape Audit Tool. Prev Chronic(12), 150098. https://doi.org/10.5888/pcd12.150098

Sallis, J., Cerin, E., Conway, TL., Adams, MA., Frank, LD., Pratt, M., Saldo, D., Schipperijn, J., Snith, G., Cain, KL., Davery, R., Kerr, J., Lai, PC., Mitás, J., Reis, R., Sarmiento, OL., Schofield, G., Troelsen, J., Van Dyck, D., De Bourdeaudhuij, I. \& Owen, N. (2016). Physical activity in relation to urban environments in 14 cities worldwide: a cross-sectional study. The Lancet 387(10034), 2207-2217. https://doi. org/10.1016/s0140-6736(15)01284-2 
Sallis, J. F., Floyd, M. F., Rodríguez, D. A., \& Saelens, B. E. (2012). Role of built environments in physical activity, obesity, and cardiovascular disease. Circulation 125(5), 729-37. https://doi.org/10.1161/circulationaha.110.969022

Seidman, M. \& Standring, R. (2010). Noise and quality of life. International Journal of Environmental Research on Public Health, 7(10), 3730-8. https://doi.org/10.3390/ ijerph7103730

Sillano, M., Greene, M. \& Ortúzar, JdD. (2006). Cuantificando la percepción de inseguridad ciudadana en barrios de escasos recursos. EURE 32(97), 17-35. https://doi.org/10.4067/ s0250-71612006000300002

Speck J. (2012). Walkable City: How Downtown Can Save America, One Step at a Time. New York: North Point Press.

Steinmetz-Wood, M., Velauthapillai, K., O’Brien, G., \& Ross, N. (2019). Assessing the micro-scale environment using Google Street View: the Virtual Systematic Tool for Evaluating Pedestrian Streetscapes (Virtual-STEPS). BMC Public Health (19), 1246. https://doi.org/10.1186/s12889-019-7460-3

Strauss, A. \& Corbin, J. (1990). Basics of qualitative research. Grounded theory procedures and techniques. Newbury Park: Sage.

StroneggerW., Titze S. \& Oja, P. (2010). Perceived characteristics of the neighborhood and its association with physical activity behaviorand self-rated health. Health \& Place, 16(4), 736-743. https://doi.org/10.1016/j.healthplace.2010.03.005

Tonucci, F. (2004). La ciudad de los niños: un modo nuevo de pensar la ciudad. Madrid: Fundación Germán Sánchez Ruiperez.
Valenzuela-Montes, L. \& Talavera-García, R. (2015). Entornos de movilidad peatonal: una revisión de enfoques, factores y condicionantes. EURE (Santiago), 41(123), 5-27. https:// doi.org/10.4067/s0250-71612015000300001

Valenzuela-Van Treek, E. \& Toledo-Alarcón, C. (2017). Pugna por gobernanza urbano-metropolitana en Chile: resistencia de agencias y reforma intergubernamental con poder regional. Urbano 20 (35), 18-31. https://

Van Dyck, D., Cerin, E., Conway, T.L., De Bourdeaudhuij, I., Owen, N., Kerr, J., Cardon, G., Frank, L.D., Saelens, B.E. \& Sallis, J.F. (2012). Perceived neighborhood environmental attributes associated with adults' transport-related walking and cycling: Findings from the USA, Australia and Belgium. International Journal of Behavioral Nutrition and Physical Activity 9, 70. https://doi.org/10.1186/14795868-9-70

Williams P.T. \& Thompson P.D. (2013). Walking Versus Running for Hypertension, Cholesterol, and Diabetes. Arteriosclerosis, Thrombosis, and VascularBiology, 33(5). 1085-1091. https:// doi.org/10.1161/atvbaha.112.300878

Wittig, R. (1993). Flora und Vegetation. In: Sukopp, R. \& Wittig, R (Eds.), Stadtökologie. Stuttgart: Gustav Fischer Verlag.

Whyte, W. H. (1980). The Social Life of Small Urban Spaces. New York: Project for Public Spaces.

Yuen, B. (2019). Ageing and the Built Environment in Singapore. Cham: Springer.

Zacharias, J. (2001). Pedestrian Behavior and Perception in Urban Walking Environments. Journal of Planning Literature, 16(1), 3-18. https://doi.org/10.1177/08854120122093249 